\title{
THE USE OF SATELLITE IMAGES IN THE FIELD OF AGRICULTURE
}

\author{
Nastasija Grujić', Marina Golubović', Dušan Jovanović
}

Received: March 12, 2017 | Accepted: May 21, 2017

\begin{abstract}
The use of remote sensing in the field of agriculture is very diverse. It includes detection of the amount of chlorophyll in crops, the amount of water, the detection of pests, the creation of maps for selective spraying and feeding, etc. In this work, different vegetation indices were applied on satellite imageries obtained from platforms: Sentinel2, Landsat8, RapidEye, and PlanetScope, in order to detect trends in the vegetation of different cultures. RapidEye and PlanetScope imageries were used in order to detect nitrogen variation for agricultural parcels in the area of the municipality of Becej. In this case indices NDVI, NDRE, and MSAVI2 are applied for cultures: corn, sunflower, wheat, sugar beet, and soybean. Sentinel2 and Landsat8 imageries were used for the analysis of the orchard near Celarevo in the municipality of BackaPalanka and analysis of agricultural parcel with a predominantly agricultural crop near Stapar in the municipality of Sombor. The detection of an area with health and non-health vegetation was made, as well as a comparison of the obtained vegetation trends between two platforms. The applied indices were: NDVI, TNDVI, GNDVI, EVI2, WDRVI, and GLI.
\end{abstract}

Keywords: remote sensing, agricultural, satellite platforms, vegetation index

APSTRAKT: Primena daljinske detekcije u oblasti poljoprivredne proizvodnje je veoma raznovrsna, od detekcije količine hlorofila u usevima, količine vode, detekcije korova i štetočina, izrada mapa za selektivno prskanje, prehranjivanje, itd. U ovom radu su primenjeni različiti vegetacioni indeksi na snimke dobijenih sa platformi: Sentinel2, Landsat8, RapidEye i PlanetScope u cilju detekcije trendova stanja vegetacije različitih kultura. RapidEye i PlanetScope snimci su iskorišćeni za poljoprivredne parcele u opštini Bečej zarad detekcije varijabilnosti azota. U ovom slučaju prmenjeni su indeksi NDVI, NDRE i MSAVI2, za sledeće gajene biljke: kukuruz, suncokret, pšenica, šećerna repa i soja. Sa Sentinel2 i Landsat8 snimcima je analiziran voćnjak kod Čelareva u opštini Bačka Palanka i poljoprivredna parcela sa pretežno ratarskom kulturom kod Stapara u opštini Sombor. Izvršena je detekcija područja sa dobrim i lošim stanjem vegetacije, kao i poređenje dobijenih trendova stanja vegetacije između dve platforme. Upotrebljeni su indeksi: NDVI, TNDVI, GNDVI, EVI2, WDRVI i GLI.

Ključne reči: daljinska detekcija, poljoprivreda, satelitske platforme, vegetacioni indeks

Faculty of Technical Sciences, University of Novi Sad, contact: nastasija1994@outlook.com 


\section{INTRODUCTION}

Production of quality agricultural goods is a primary focus for each country. Nowadays, the development of science and technology effects agriculture to reach its peak through the application of geospatial technologies which involve the collecting of a large amount of quality data as well as its analysis and interpretation. In the most cases, collecting data is done using remote sensing, which contributes monitoring of large areas for the purpose of planning, forecasting and management strategies for agricultural resources. In order to emphasize the individual properties of plants, the mathematical combination of different values of spectral ranges is made. These combinations represent the vegetation indices (VI further) which are designed to point up the level of plant stress, nitrogen, chlorophyll, water, biomass estimation, yields, etc.

In this work NDVI, NDRE and MSAVI2 vegetation indices were applied on the satellite imageries from RapidEye and PlenetScope platforms, in order to detect nitrogen variability on the agricultural-cultivated crops: corn, sunflowers, wheat, sugar beet and soybean in the municipality of Becej. Moreover, NDVI, TNDVI, GNDVI, WDRVI, GLI and EVI2 vegetation indices were applied on the satellite images from Sentinel2 and Landsat8 platforms for the purpose of detecting trends of good and bad vegetation conditions, with a special review of the comparative analysis of the results obtained on both platforms.

\section{SATELLITE CONSTELLATIONS}

\section{Landsat8}

Landsat 8 is the eight satellites of Landsat series, developed and launched by NASA in 2013. It has the ability to record spectral energy in 11 ranges with a spatial resolution of $15 \mathrm{~m}$ to $100 \mathrm{~m}$ and temporal resolution of 16 days.

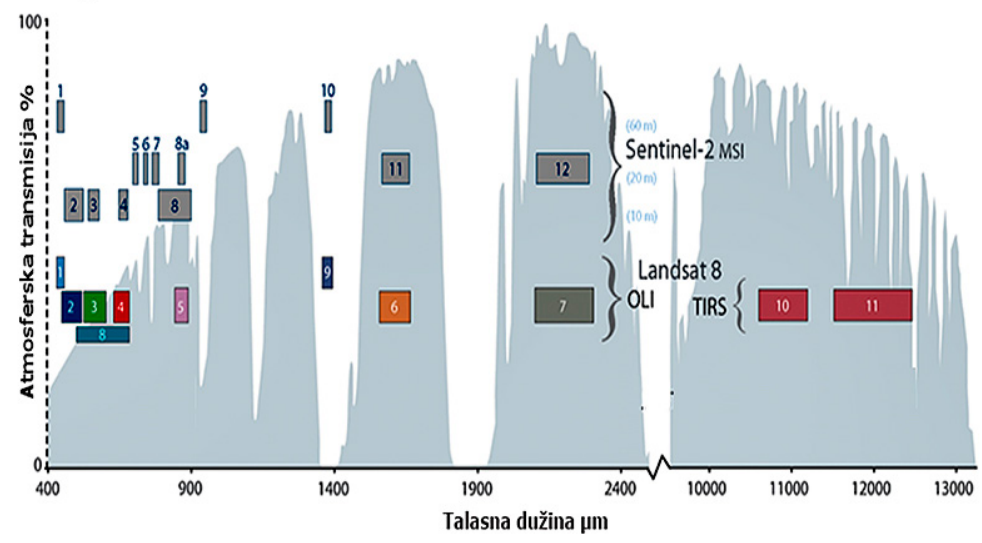

Figure 1. Spectral bands of Landsat8 and Sentinel2 [2] 


\section{Sentinel2}

Sentinel 2 constellation has been developed by the ESA, and it consists of 2 satellites capable of capturing energy in 13 spectral ranges. Temporal resolution is 5 days. Comparative overview of the spectral bands of Sentinel 2 and Landsat 8 missions are represented on Figure 1.

\section{RapidEye}

RapidEye has a constellation of 5 identical satellites with the spatial resolution of $5 \mathrm{~m}$. It records energy in 5 spectral bands. The high temporal resolution of $24 \mathrm{~h}$ is one of the main characteristics of this platform.

\section{PlanetScope}

PlanetScope constellation has approximately 150 satellites with the spatial resolution of $3 \mathrm{~m}$. It records energy in 4 spectral bands.

\section{Vegetation indices}

1. NDVI (Normalized Difference Vegetation Index) is used for global vegetation analysis, based on linear regression of NDVI values with direct examination of LAI, APAR and biomass factor. It shows problems in scaling with saturated signals that often occur under high biomass condition of the forest regions,which is more favorable in the areas of low biomass. [7]

$$
N D V I=\frac{N I R-R E D}{N I E+R E D}
$$

2. TNDVI (Transformed Normalized Difference Vegetation Index) is designed to have a higher coefficient of the decisiveness which is the only difference between NDVI and itself. [5]

$$
T N D V I=\sqrt{\frac{N I R-R E D}{N I E+R E D}}
$$

3. GNDVI (Green Normalised Difference Vegetation Index) is modified version of NDVI which uses a green band instead of a red. It is more sensitive to the variation of chlorophyll in plants. Also, a lower sensibility of the index was determined, for the presence of nitrogen in the plant than NDVI.[5]

$$
G N D V I=\frac{N I R-G R E E N}{N I E+G R E E N}
$$


4. EVI2 (The enhanced vegetation index 2) is developed for optimization of vegetation signal in order to increase sensibility in high biomass regions and to improve monitoring of vegetation. Also, it reduces the atmospheric effect on vegetation signal. Unlike NDVI, which is sensitive to chlorophyll, EVI2 is more sensitive to structural variations in the canopy. So it is often used for trees canopy classification.[9]

$$
E V I 2=G \frac{N I R-R E D}{N I R+C_{1} R E D-C_{2} B L U E+L}
$$

5. WDRVI (The Wide Dynamic Range Vegetation Index) is designed to overcome some limitations of NDVI by introducing a weight factor on NIR band in the formula of NDVI. If medium to high biomass is analyzed (LAI $>2$ ), it is recommended to use WDRVI, while for low vegetation (LAI $<1)$, NDVI is a better solution.[1]

$$
W D R V I=\frac{a N I R-R E D}{a N I R+R E D}
$$

6. GLI (Green Leaf Index) uses only visible part of the spectrum. It is sensitive to the presenceof chlorophyll and nitrogen in plants. It gives better results for moderate to dense biomass.[5]

$$
G L I=\frac{2 G R E E N-R E D-B L U E}{2 G R E E N+R E D+B L U E}
$$

7. NDRE (Normalized Difference Red Edge) represents the modification of NDVI, where the red band is replaced with red edge band, which is more sensitive to chlorophyll variations.[8]

$$
N D R E=\frac{N I R-R e d E d g e}{N I R+R e d E d g e}
$$

8. MSAVI2 (Modified Soil Adjusted Vegetation Index2) is developed in order to improve NDVI performances, especially when it is applied on the areas with high level of soil exposure. It is designed specificallyfor areas with low vegetation to reduce the soil effect. [8]

$$
M S A V I 2=\frac{\left(2 \cdot N I R+1-\sqrt{(2 \cdot N I R+1)^{2}-8 \cdot(N I R-R E D)}\right.}{2}
$$




\section{PROCESSING DATA}

\section{Atmospheric correction}

An important source of radiometric errors arises from the atmospheric weakness caused by the dissipation and absorption of EM energy by the atmosphere.When it is necessary to extract biophysical parameters of water masses or vegetation (chlorophyll, biomass, etc.) from satellite imageries, the use of atmospheric correction is mandatory.

The atmospheric correction of Landsat8 imageries was performed in QGIS software, where is also performed sharpening of the other bands based on the pan band - pansharpening algorithm. [4] Atmospheric correction was performed in Sen2Core software for Sentinel2, while Erdas Imagine software was used for RapidEye and PlanetScope.

\section{Applicability of vegetation idicesand classification}

The used vegetation indices were applied within the Erdas Spatial Model Editor tool, which allows the graphical creation of the flow of events and its execution. After the creation of the VI, next step was coloring the obtained raster known as engineering classification.Simple engineering classification was made for easier visual observation of the state of vegetation - trends.It was done in Erdas Knowledge Engineer tool. It was performed on 20 equal ranges. The used color range was from red to green (Figure 2). In order to detect locations of the same anomalies, an engineering classification with several decision parameters was done within the mentioned tool. There were multiple rasters (in this case VI) in the input and their classification was done according to certain rules (values) corresponding to the observed anomaly. The result is a raster with identifies areas that have a given range of values on all inputs.

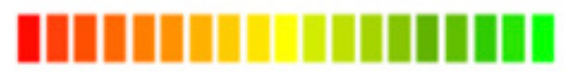

Figure 2. The used color range

\section{RESULTS OF THE PROCESSING OF PLANETSCOPE AND RAPIDEYE FOOTAGE - MUNICIPALITY OF BECEJ}

The analysis of the variance of the nitrogen was performed in the period from April to July by RapidEyeimageries. Figure 3 shows theclassification results after applying the NDVI index for parcels under corn. The marked part of the parcel represents the potential place of the missing of nitrogen concentration or excess of it.

For the corresponding parcels of sunflower,the results of the MSAVI2 index application are shown, as well as the identified sites of potential changes are characterized by the low reflection value. (Figure4)

The application of the NDRE index, which is highly correlated with nitrogen variation, is shown in Figure 5 for the wheat culture and Figure 6 for the soybean culture. 

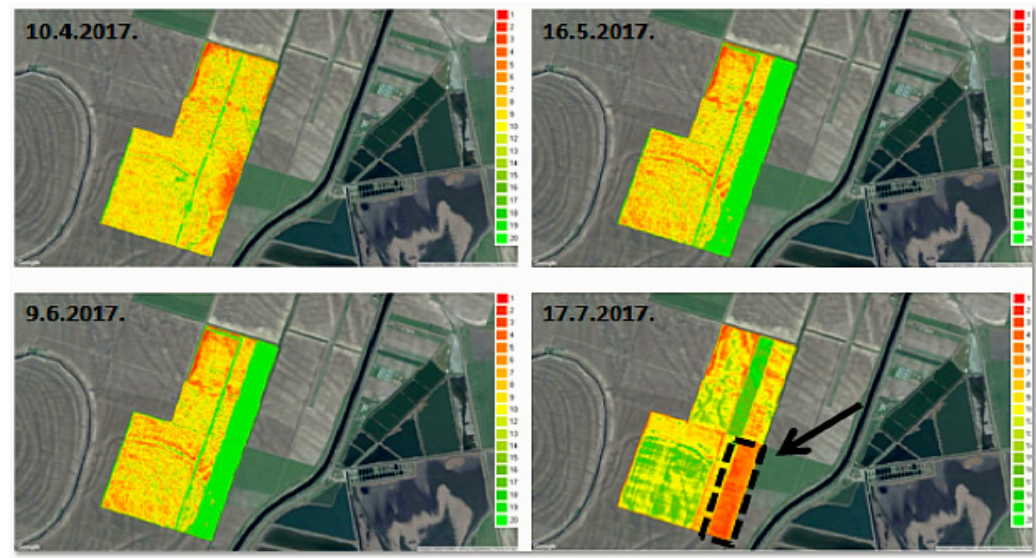

Figure 3. Results of MSAVI2 index (corn)
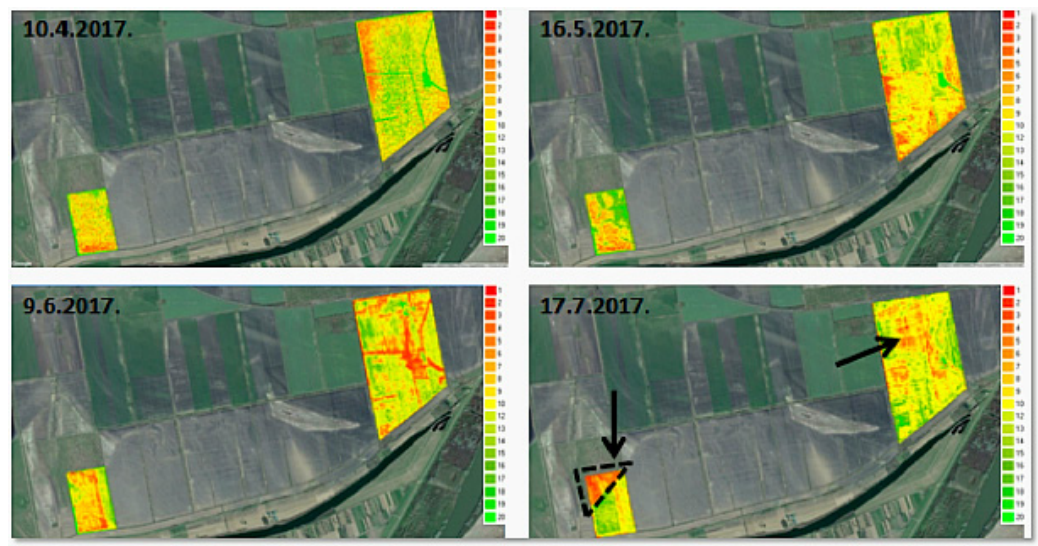

Figure 4. Results of MSAVI2 index (sunflower)
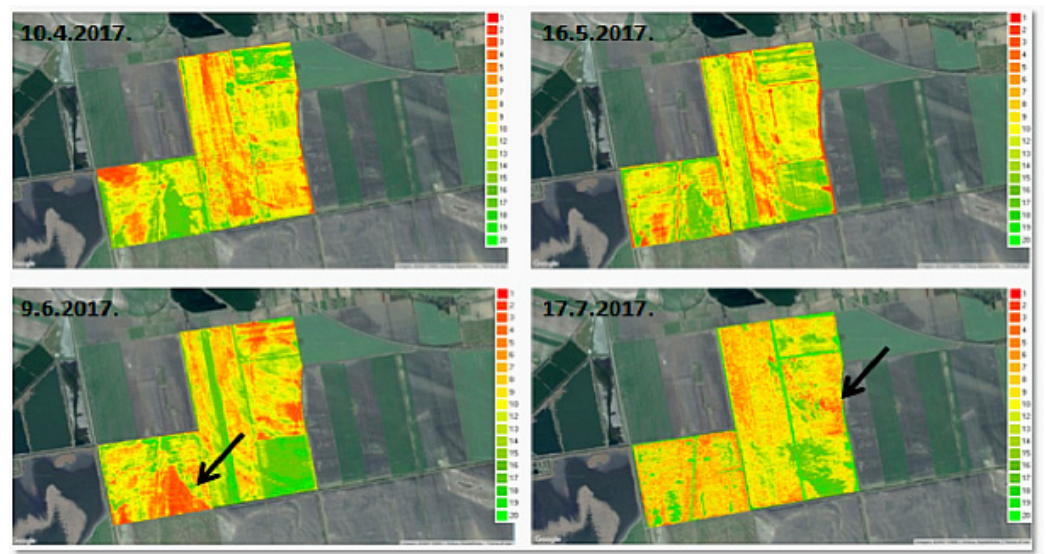

Figure 5. Results of NDRE index (wheat) 

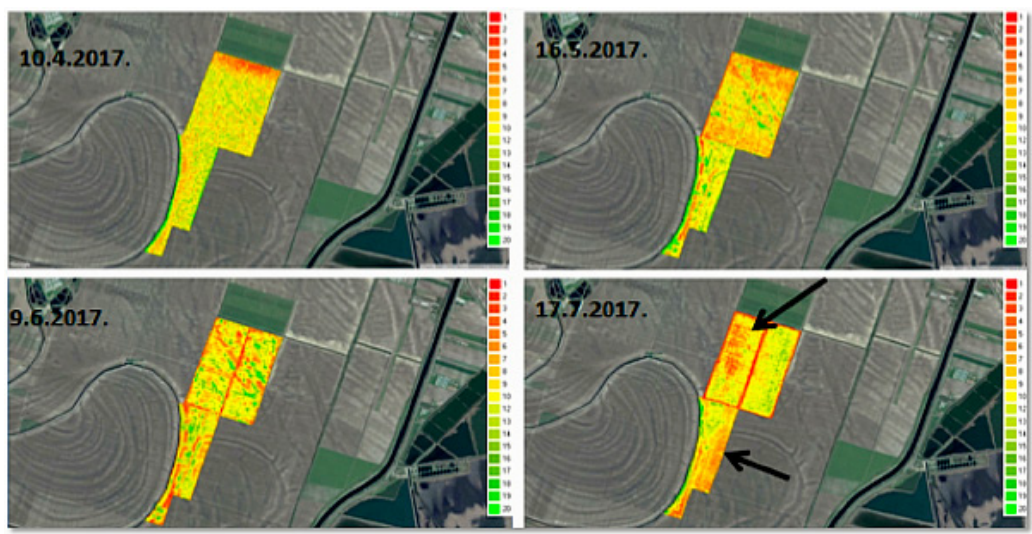

Figure 6. Results of NDRE index (soybean)

Throughout all four time moments of the analysis of the images, the low reflection rate prevails with a very small percentage of healthy vegetation (green parts of the parcel).

The use of the MSAVI2 indexis shown in Figure 7 on sugar beet plots.The anomaly with potential excess or deficiency of nitrogen is marked.
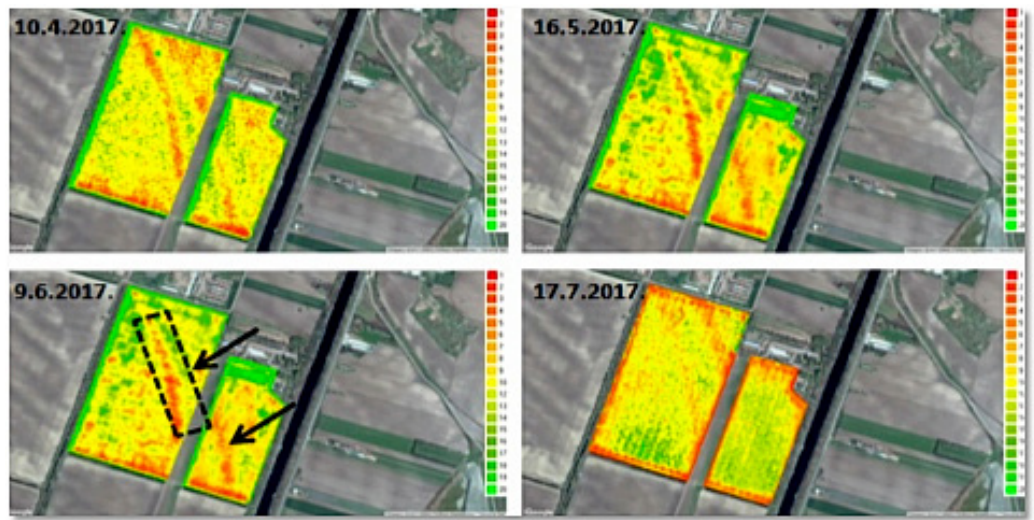

Figure 7. Results of MSAVI2 index (sugar beet)

RapidEye and PlanetScopeimageries were used for date 9.6.2017.in order to make the comparative analysis, with the accent on a better spatial resolution of the PlanetScope imagery - 3m (Figure 8). 


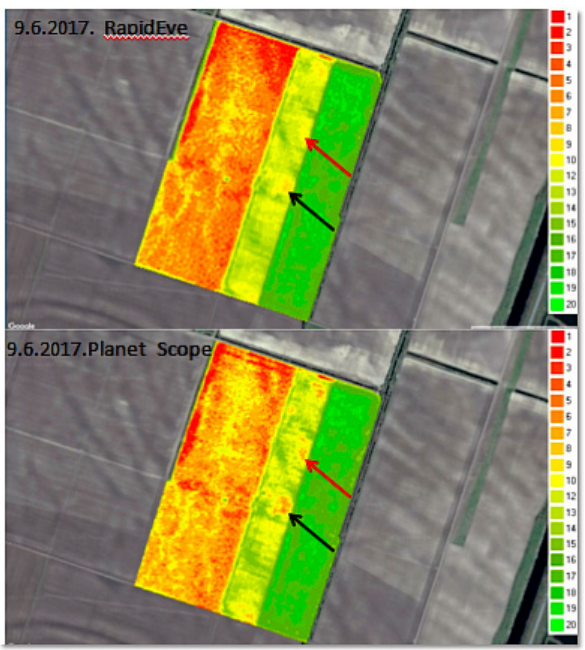

Figure 8. Results of NDVI index for RapidEye and PlanetScope

\section{RESULTS OF PROCESSING SENTINEL2 AND LANDSAT8 IMAGINERY- AGRICULTURAL PLOTS IN CELAREVO AND STAPAR}

On Figures 9, 10 and 11are showna comparative overview of the results obtained for the orchard at Celarevo on Sentinel2 (left) and Landsat8 (right) imagery on 24.6.2017.

On each pair of imageries can be noted the same trends of health and non-health vegetation; though there are some parts with deviations. A trend with less health vegetation was observed on all used indices (the area is marked in Figure 12) ranging from 90 to 195 (0-255). The engineering classification was executed for the mentioned range of values and all indices were used for the Sentinel-2 imageries from the date 4.7.2017. The result is shown in Figure 11, where can be detected a few more areas corresponding to the defined range.
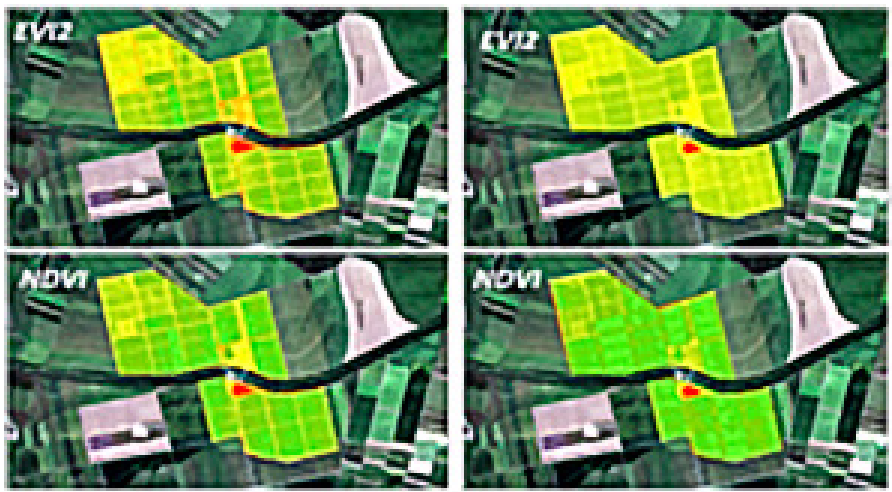

Figure 9. The results of the simple engineering classification of the EVI2 and the NDVI index for the date of 24.6.2017. 


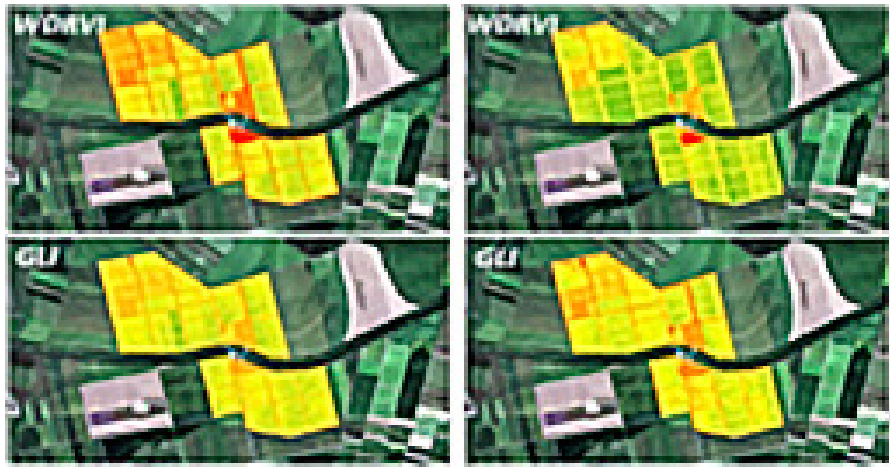

Figure 10. results of simple engineering classifications of WDRVI and GLI index for date 24.6.2017.

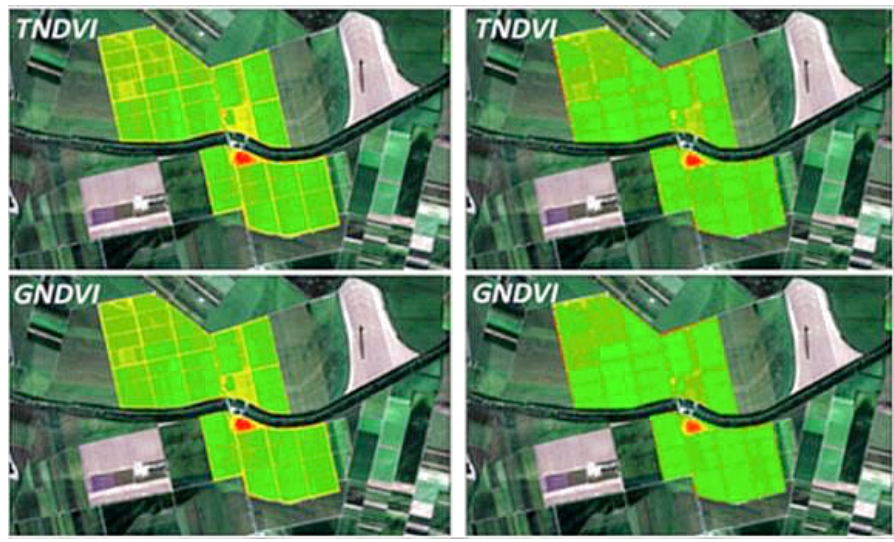

Figure 11. results of simple engineering classifications of TNDVI and GNDVI index for date 24.6.2017.

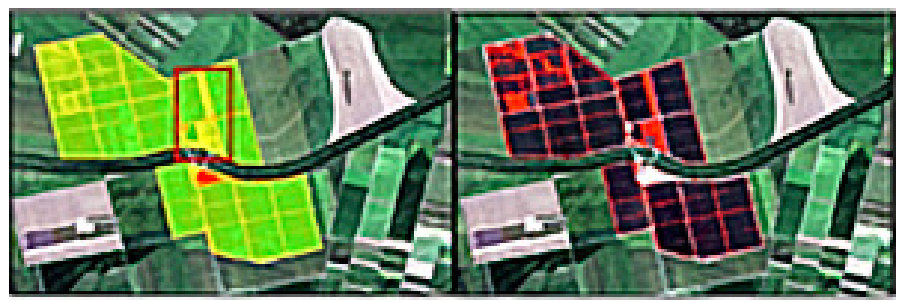

Figure 12. Observed trend - left, result - right

On Figures 13 and 14 are shown the colored vegetation indices applied to Sentinel2 (in the middle) and Landsat8 (on the sides) imagery, corresponding to the dates in the order shown: 10.7.2017, 14.7.2017, 17.7.2017. The same trends with the same values (colors) are observed between the indices.

Considering that this area is covered by low crop cultivation, WDRVI and GLI produce poorer results because they are sensitive to the presence of dense and high vegeta- 

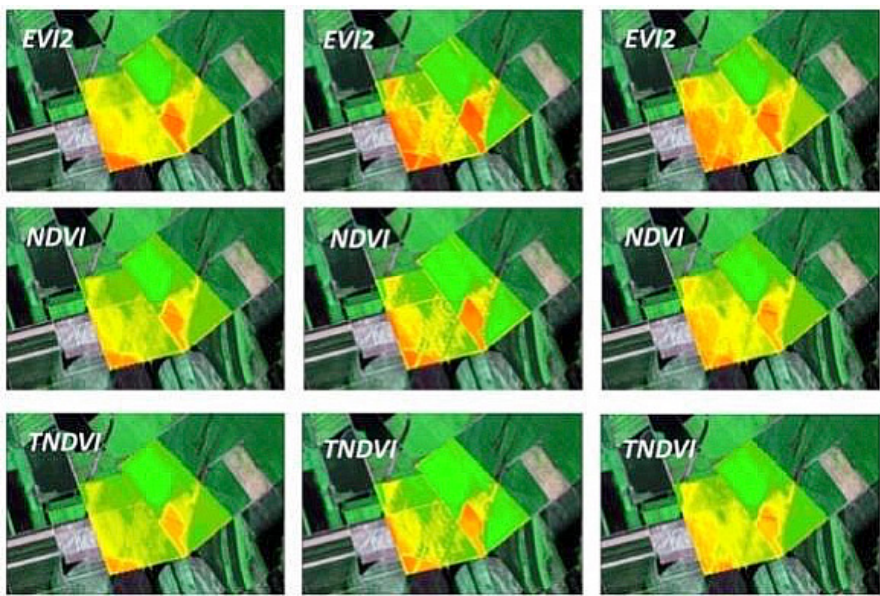

Figure 13. Results of simple engineering classifications of EVI2, NDVI and TNDVI index for the dates of 14.7.2017. (Sentinel2), 07.10.2017. and 17.07.2017. (Landsat8)
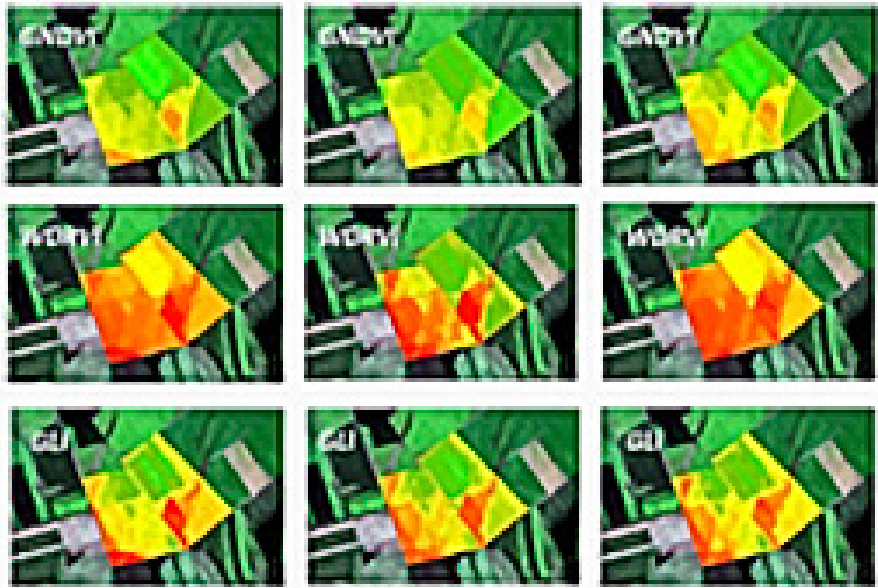

Figure 14. Results of simple engineering classifications of GNDVI, WDRVI and GLI index for dates 14.7.2017. (Sentinel2), 07.10.2017 and 17.07.2017. (Landsat8)

tion (LAI> 2). Since Stapar is three times smaller than the orchard at Celarevo, here spatial resolution comes to a very large extent; which is manifested through a rather small variation in the values of Landsat's recordings compared to Sentinel's recordings in the mention indices. Trends of the best vegetation on imageries on both platforms are in the range 220-240. In order to detect sites with best vegetation area on imageries from both platforms, engineering classification was made for the NDVI, GNDVI, TNDVI and EVI2 indices. The imagery of Sentinel 2 belong to the date: 14.7.2017, thus Landsat8 imagery belongs 17.7.2017. The results of the Sentinel2 image are shown on the left and Landsat 8 on the right in Figure 15. 


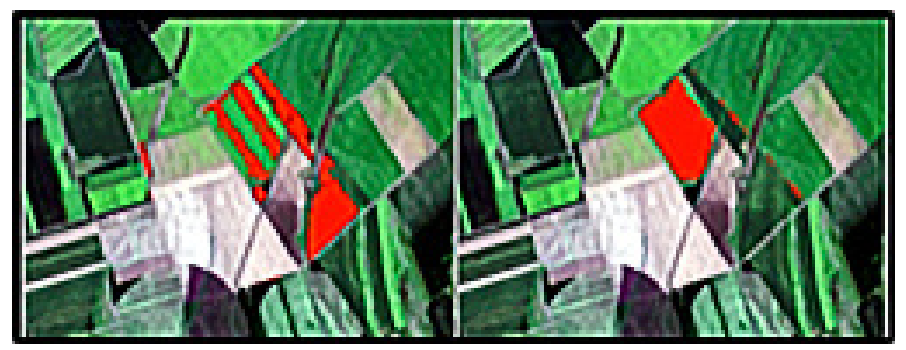

Figure 15. Results of the engineering classification for the Sentinel2 imageries from 14.7.2017. (left) and Landsat8 from 17.7.2017. (right)

\section{CONCLUSION}

Remote detection is a very important link in the chain of precision agriculture and its use enables us to obtain an accurate picture of the condition of the land and crops, i.e. plans for the selective spraying of weeds and insects, alleviation of plant diseases, determination of the amount of nitrogen, optimal irrigation, etc. Thanks to the constant development of technology, it becomes a massively accepted solution. In combination with GIS and its applications, it provides useful information to a wide range of users.

\section{LITERATURE}

Anatoly A. Gitelson (2004) "Wide Dynamic Range Vegetation Index for Remote Quantification of Biophysical Characteristics of Vegetation", 165-173

Comparison of Landsat8 bands with Sentinel2 https://landsat.gsfc.nasa.gov/sentinel-2alaunches-our-compliments-our-complements/ [1.9.2017.]

Edoardo Simonetti, etc. (2014), "Phenology-based land cover classification using Landsat 8 time series", ISSN 1831-9424

Jovanović D.,Govedarica M., Sabo F., Važić R., Popović D., (2016). "Impact analysis of pansharpeningLandasat ETM+, Landsat OLI, WorldView-2 and Ikonos images on vegetation indices." Fourth International Conference on Remote Sensing and Geoinformation of the Environment (RSCy2016)

John F. Shanahan, James S. Schepers, Dennis D. Francis, Gary E.Varvel, Wallace W. Wilhelm, James M. Tringle, Mike R. Schlemmer and Davi J. Major (2000) "Use of Remote Sensing Imagery to Estimate Corn Grain Yield."

Mario Cupertino da Silva Júnior, Francisco de Assis de Carvalho Pinto, Daniel Marçal de Queiroz, Enrique AnastácioAlves, Luis Manuel NavasGracia, Jaime Gomez Gil6 (2005) "Correlation between vegetation indices and nitrogen leaf content and dry matter production in Brachiariadecumbens", ISSN 0947-7314 pages 145-150

Rothic Pathak, Ganesh C.Bora, John F.Nowatzki, Anne M. Denton (2017) "Data Management Using Digital Imagery to Study the Correlation between NDVI and Different Stages of Crop Production to Predict Yield“ 
Troy S. Magney, Jan U. H. Eitel, Lee A.Vierling (2016) "Mapping wheat nitrogen uptake from RapidEye vegetation indices.“

Zhangyan Jiang, Alfredo R.Huete, KamelDidan, Tomoaki Miura (2008) "Development of a two-band enhanced vegetation index without a blue band" 